\title{
Metals in environmental media: A study of trace and platinum group metals in Thohoyandou, South Africa
}

\author{
John Ogony Odiyo, Hendricks Maboladisoro Bapela, Ronald Mugwedi and Luke Chimuka* \\ School of Environmental Sciences and Engineering, University of Venda, P/Bag x5050, Thohoyandou 0950, South Africa
}

\begin{abstract}
A detailed study has been conducted to determine the contamination of Thohoyandou roadside soils, vegetation, sewage and river waters by $\mathrm{Zn}, \mathrm{Cu}, \mathrm{Cr}, \mathrm{Pb}, \mathrm{Cd}, \mathrm{Fe}, \mathrm{Pt}$ and $\mathrm{Pd}$. The study further investigated the correlation between these trace metals in roadside soils and vegetation in order to infer the potential impacts of roadside trace metals contamination of vegetation. Collected surface soil and vegetation samples were analysed with atomic absorption spectrophotometer for $\mathrm{Zn}, \mathrm{Cu}, \mathrm{Cr}, \mathrm{Pb}$ and $\mathrm{Cd}$ while water samples were analysed by inductively coupled plasma atomic emission spectrometry (ICP-OES) for $\mathrm{Zn}, \mathrm{Cu}, \mathrm{Fe}, \mathrm{Pt}$ and Pd. A linear correlation was observed between soil and vegetation metal concentration, which suggests the same source of metals in the samples except for $\mathrm{Cu}$. The findings also revealed a general reduction in soil and vegetation metal concentrations some distance away from road traffic. For both experimental soil and vegetation samples, the mean concentrations were found to follow the decreasing orders: $\mathrm{Pb}>\mathrm{Zn}>\mathrm{Cr}>\mathrm{Cu}>\mathrm{Cd}$ and $\mathrm{Pb}>\mathrm{Zn}>\mathrm{Cd}>\mathrm{Cr}>\mathrm{Cu}$ respectively. For water samples, trace metals were highest in raw sewage and lowest in river waters. The sewage system leaking directly into the rivers was found to be the major source of pollution by trace metals. The mean concentrations of the trace metals in the water bodies were found to follow the following decreasing order: $\mathrm{Fe}>\mathrm{Zn}>\mathrm{Pt}>\mathrm{Cu}>\mathrm{Pd}$.
\end{abstract}

Keywords: trace metal contamination; roadside soil; vegetation; water; Thohoyandou, South Africa

\section{Introduction}

$\mathrm{Zn}, \mathrm{Cu}, \mathrm{Pb}, \mathrm{Fe}, \mathrm{Cd}$ and $\mathrm{Cr}$ are trace metals that commonly cause pollution of urban environments. Motor vehicles and sewage systems constitute some of the major sources that release these metals directly into the urban environments (Fatoki, 1996; Fatoki and Ayodele, 1991; Sörme and Lagerkvist, 2002). Metals from vehicle emissions are released into the atmosphere and are subsequently deposited into the surrounding soil, vegetation and water bodies. These metals can also leach from the roadsides during rains to surrounding water bodies. Poorly maintained sewage systems can also be a major source of trace metal contamination, especially if there are pipes leakages.

Several researchers (Fatoki, 1996; Fatoki and Ayodele, 1991; Sithole et al., 1993; Onyari et al., 2002; Okonkwo et al., 2003) have reported elevated concentrations of trace metals even as far as $250 \mathrm{~m}$ from the roadside. Vehicle exhausts, lubricating oils, tyres and plating materials have been cited as components that contain one or more of these metals (Lagerwerff and Specht, 1970; Ward et al., 1977). Roofing materials, food wastes, sewage system pipes and taps are among the major sources of trace metals in the sewage (Sörme and Lagerkvist, 2002). Under normal circumstances, the major sources of these metals are heavy industries such as mining and metal industries.

$\mathrm{Zn}, \mathrm{Cu}, \mathrm{Fe}$ and $\mathrm{Cr}$ are all essential elements for many plants, animals and man but at trace levels. At high concentrations, they are all potentially toxic (Nyriagu, 1988; Goyer, 1996). Pb and $\mathrm{Cd}$ are generally regarded as toxic elements even at trace levels (Goyer, 1996). It has been shown by Morton et al. (2001), Moldovan et al. (2001) and Ravindra et al. (2004) among oth-

* To whom all correspondence should be addressed.

푱 +2715 9628573; fax: +2715 9628597;

e-mail: LukeChimuka@hotmail.com; Chimuka@univen.ac.za

Received 28 February 2005; accepted in revised form 21 June 2005. ers that Pt and Pd released by automobile catalytic converters accumulate to contaminant concentrations with time in roadside soils, water and vegetation. Morton et al. (2001) reported concentrations of $\mathrm{Pt}, \mathrm{Pd}$ and $\mathrm{Rd}$ in roadside soil samples from Mexico City of 300, 70 and $40 \mu \mathrm{g} / \ell$, respectively. Despite the low quantities of these Pt group elements (PGE) emitted from catalytic converters, the accumulation of these elements in soils, water and plants along heavily travelled roads rises with their use (Morton et al., 2001). Monitoring of these metals in urban environments is therefore critical as it gives vital information as to whether exposure concentrations can cause adverse effects especially to humans.

This study attempted to investigate the contamination of soil, vegetation and water bodies within Thohoyandou peri-urban town by $\mathrm{Zn}, \mathrm{Cu}, \mathrm{Cd}, \mathrm{Pb}, \mathrm{Cr}, \mathrm{Fe}, \mathrm{Pt}$ and $\mathrm{Pd}$. The study further correlated the soil and vegetation metal concentrations in the study area. Similar studies (Mathee and Schirnding, 2002) have been concentrated in major cities in South Africa at the expense of small or peri-urban towns like Thohoyandou. The previous study by Okonkwo et al. (2003), investigated only $\mathrm{Pb}$ pollution in soil and vegetation along the major Thohoyandou roads. The study left out $\mathrm{Zn}, \mathrm{Cd}, \mathrm{Cu}, \mathrm{Cr}$ and $\mathrm{Pt}$ group metals which are common trace metals and emerging contaminants, respectively. Okonkwo et al. (2003) study, did not investigate the level and presence of these contaminants in surface water bodies which is equally important since the surrounding community depend on it for household and agricultural activities. Okonkwo and Mothiba (2005) study on pollution levels of trace metals in rivers in Thohoyandou apart from not considering pollution in soil and vegetation also left out Pt group metals. None of the two studies directly investigated pollution link to sewage system. Thohoyandou town has also seen an increase in both population and traffic since the end of the old system of government. This is evidenced by the continued expansion of central business district, residential areas and traffic congestion at peak hours. 


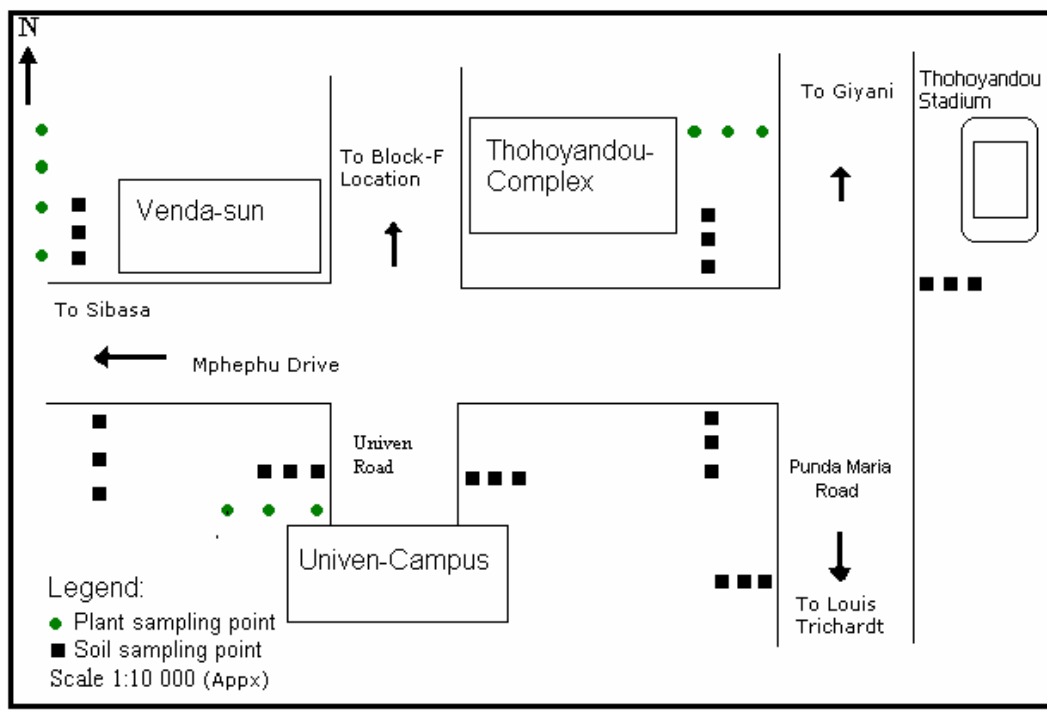

Figure 1

Plan of sampling

site, showing

roadways covered

\section{Materials and methods}

\section{The study area and sampling}

The roads that are all tarred (Sibasa, Univen and Punda Maria) and shown in the sampling plan (Fig. 1) were chosen for the study because they have the heaviest traffic in the town. The soils, the water and the plants in the neighbourhoods of these roads are likely to be threatened by pollution from motor vehicle exhaust emissions than those in the neighbourhoods of the other Thohoyandou roads with less traffic.

Twenty-four soil samples and ten plant samples excluding 'controls' were collected perpendicular to the roads at different selected sampling points (Fig. 1) in clean plastic bags. The soil sampling spots were cleared of all the debris before sampling. Only topsoil was sampled from a depth of 0.25 to $5 \mathrm{~cm}$ using a hand shovel. Soil samples weighing above $200 \mathrm{~g}$ were then sealed in polythene plastic bags for laboratory analysis. Samples were collected from both sides of the Sibasa, Univen and Punda Maria roads as shown in Fig. 1. Six soil samples were collected at distances of 20 and $70 \mathrm{~m}$ away from the last experimental road points, in undisturbed sites, relatively unaffected by human activities. These 'control' samples were collected so as to validate the consistency in reduction of metal concentration with distance from the road and to eliminate other sources.

Fresh plant leaves from the Lantana camara species were collected at a height of $1 \mathrm{~m}$ above the ground, using a pair of scissors. Plant samples were taken on both sides of the roads, except where the vegetation was cleared due to current settlement developments. Lantana camara was chosen because it is a plant species that grows along most of the roads in Thohoyandou area. The shrub can grow up to a height of $3 \mathrm{~m}$. The species belong to the Verbenaceae family. Three 'control' plant samples were collected at distances of about $60 \mathrm{~m}$ from the last experimental road points.

Water samples from rivers (Mvudi, Madanzhe) within Thohoyandou peri-urban town (Fig. 2) were collected so as to study any leaching of the metals from the land into the rivers. Twenty samples were collected in clean plastic containers from streams and rivers within Thohoyandou as shown in Fig. 2. Each of these was achieved by lowering the container into the water about 100 to $300 \mathrm{~mm}$ below the surface with the open end facing

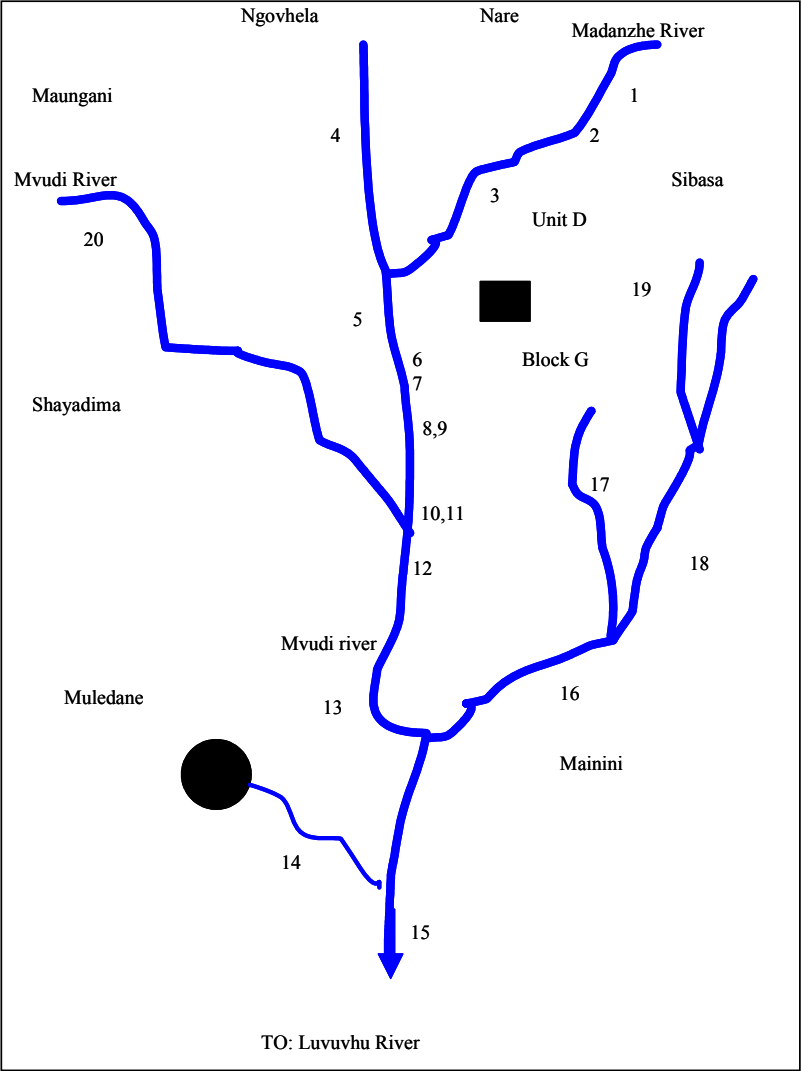

Figure 2

Loactions of the sampling areas along the rivers and streams within Thohoyandou town residential areas.

Legend: • biological wastewater treatment plant for the town, - location of the Thohoyandou city center.

against the current flow direction. If there was no current, it was created artificially by stirring the water. The containers were closed inside the water body.

Water samples were collected upstream, mid-stream and downstream. These sampling sites were systematically chosen after an initial site survey. The site survey revealed that there were leakages from sewage system pipes between residential areas and the treatment plant. The leakages were observed 
to discharge directly into the water bodies. The sewage as it emerged from broken pipes was also collected and it allowed determining how much of the heavy metals pollution into the rivers came from the sewage system. The collected samples were stored in the refrigerator at $4^{\circ} \mathrm{C}$ until sample testing time.

\section{Sample preparation procedures}

The sample preparation procedure previously used by Ndou (2002) was followed for soil and plant samples. In brief, soil samples were first dried at room temperature. They were later ground using clean mortar and pestle and then passed through a laboratory test sieve with $500 \mu \mathrm{m}$ apertures to obtain fine soil particles. One gram of each soil sample was taken in a $250 \mathrm{~m} \ell$ clean conical flask and moistened with a few drops of water to prevent any sputtering. Then $10 \mathrm{~m} \ell$ of concentrated $\mathrm{HNO}_{3}$ was added to the soil. The mixture was digested on a hotplate inside a fume hood to bare dryness. The soil residue obtained was then digested with a mixture of concentrated acids containing $\mathrm{HNO}_{3}(5 \mathrm{~m} \ell)$, $\mathrm{HCL}(5 \mathrm{~m} \ell)$ and $\mathrm{HCLO}_{4}(5 \mathrm{~m} \ell)$ for $10 \mathrm{~min}$ at room temperature. The mixture was digested further on a hotplate inside a fume hood to a final volume of $5 \mathrm{ml}$ and filtered using the Whatman No.1 filter paper into a $100 \mathrm{~m} \ell$ volumetric flask. The contents of the flask were then diluted up to the mark with distilled deionised water. Soil samples for 'control' were treated with the same procedure as the experimental samples.

Plant leaves were washed with deionised water to remove any particulate matter that may have been deposited on the leaves from the atmosphere, and then dried at room temperature. The dried plant leaves were repeatedly crushed in a clean pestle and mortar and passed through a brass laboratory test sieve with $500 \mu \mathrm{m}$ apertures to obtain fine leaf particles. About 1 to $2 \mathrm{~g}$ of sieved leaf samples were weighed into $250 \mathrm{~m} \ell$ conical flasks. The samples were then digested with a mixture of $\mathrm{HNO}_{3}(20 \mathrm{~m} \ell)$ and $\mathrm{HCLO}_{4}(8 \mathrm{~m} \ell)$ in a fume hood to a final volume of $5 \mathrm{m \ell}$. Some deionised water was added and the solution filtered with Whatman No. 1 filter paper into a $100 \mathrm{~m} \ell$ volumetric flask. Samples were later diluted to the mark with deionised water. Plant samples for 'control' were treated in the same way as experimental samples.

A method previously described by Okonkwo and Mothiba (2005) was used for preparing water samples for analysis. In brief, collected river water samples were filtered through Whatman No. 1 filter paper into clean plastic containers and stored in the refrigerator at $4^{\circ} \mathrm{C}$ until analysis. A sample aliquot of $50 \mathrm{m \ell}$ of raw sewage was transferred into $500 \mathrm{~m} \ell$ Pyrex conical flask and $2.5 \mathrm{~m} \ell$ of concentrated nitric acid $\left(\mathrm{HNO}_{3}\right)$ was added to it. The sample was then boiled until clear solution appeared on the heating mantle in the fume cupboard. It was allowed to cool and then filtered using Whatman filter paper, its volume measured and stored in plastic containers in the refrigerator at $4^{\circ} \mathrm{C}$ until analysis.

\section{$\mathrm{pH}$, total dissolved solids and conductivity measurements}

The $\mathrm{pH}$ measurements of the soil were determined using sieved soil samples. Three grams of soil samples were weighed in clean $50 \mathrm{~m} \ell$ glass beakers. Deionised water was added to form a slurry solution from which $\mathrm{pH}$ measurements were made with the $\mathrm{pH}$ meter. Before use, the $\mathrm{pH}$ meter was calibrated with standards with buffers of $\mathrm{pH}$ solutions $\mathrm{pH} 7$ and 4 . The $\mathrm{pH}$ and the conductivity of the water samples were done immediately after sample collection in the laboratory by immersing the calibrated $\mathrm{pH}$ and conductivity meter probes into the samples until the readings stabilised.

SS was determined as follows: A clean filter paper was placed in the oven and heated to $100^{\circ} \mathrm{C}$ for $10 \mathrm{~min}$ to remove any moisture. It was then placed on the weighing balance and its weight recorded upon which $50 \mathrm{~m} \ell$ of the sample was filtered using a funnel containing filter paper. The filter paper was then placed in the oven, heated as above, cooled and re-weighed. The first weight was subtracted from the second one to obtain the total suspended solids for the particular sample.

\section{Sample analysis}

The flame atomic absorption spectrophotometer (Varian Spectra AA 220) was used to measure the concentration of total trace metals in the soil and plant samples. Calibration was done using certified standards from Industrial Analytical (Pty) Ltd. (Johannesburg, South Africa). Working standards of 0.5 to $10 \mathrm{mg} / \ell$ concentrations were prepared from $1000 \mathrm{mg} / \ell$ stock solutions. All solutions were prepared in deionised water. For water samples, an inductively coupled plasma emission spectrometer (ICP-OES) from Spectro Analytical Instruments Inc, Kleve-Germany was used. Concentration range of the standards was from 0.030 to $1.0 \mathrm{mg} / \ell$. Analyses were carried out in triplicates.

\section{Results and discussion}

\section{Recovery test and precision}

The recovery test and reproducibility of the method were not fully investigated. However, the same procedure as that of Ndou (2002) was followed for soil and plant samples. Ndou (2002) did a similar study in the same area on soils and plants but restricted it to $\mathrm{Pb}$ metal pollution of soils and vegetation in Thohoyandou. The sample preparation procedure was found to be efficient and reliable with mean percentage recoveries greater than 95 and percentage standard deviations less than 5 .

\section{$\mathrm{pH}$ of the soil}

The $\mathrm{pH}$ of the soil samples measured averaged 6.6, which is slightly acidic. Soil $\mathrm{pH}$ generally plays an important role in metal bioavailability, toxicity and leaching capability to surrounding areas especially in summertime. Heavy metals are mostly more soluble and leach out in acidic pH (Alloways, 1995). This makes them also less bioavailable to plants since they are easily washed away during rains. A soil $\mathrm{pH}$ of 6.6 could indicate that heavy metals remain in the roadside soil for a long time exposed to plants and other organisms that come into contact with them.

\section{Calibration curves}

The calibration curves for the metal ions yielded good correlation coefficients $\left(\mathrm{r}^{2}\right)$ ranging from 0.9871 to 0.9993 . This implies that the instruments responded very well to the standard analyte of interest and therefore would respond to the analyte in the samples. 


\begin{tabular}{|l|c|c|c|c|c|c|}
\hline \multicolumn{7}{|c|}{ TABLE 1 } \\
Trace metal concentrations in 'control' soil \\
samples in the vicinity of Thohoyandou roads \\
\hline Road Name & $\begin{array}{c}\text { Distance } \\
\text { from } \\
\end{array}$ & \multicolumn{5}{|c|}{ Concentrations (mg/kg) } \\
\cline { 3 - 7 } & road (m) & Cu & Zn & Cr & Pb & Cd \\
\hline Sibasa & 50 & 0.21 & 0.42 & 0.23 & 4.13 & 0.11 \\
Sibasa & 100 & 0.12 & 0.27 & 0.18 & 10.22 & 0.14 \\
Mean & & 0.16 & 0.34 & 0.20 & 7.18 & 0.12 \\
Univen & 50 & 0.83 & 0.22 & 0.41 & 3.23 & 0.10 \\
Univen & 100 & 0.61 & 0.21 & 0.21 & 1.34 & 0.24 \\
Mean & & 0.72 & 0.21 & 0.31 & 2.28 & 0.17 \\
Punda Maria & 50 & 0.63 & 0.42 & 0.28 & 4.53 & 0.10 \\
Punda Maria & 100 & 0.19 & 0.23 & 0.10 & 2.23 & 0.23 \\
Mean & & 0.41 & 0.32 & 0.19 & 3.38 & 0.16 \\
\hline
\end{tabular}

\begin{tabular}{|l|c|c|c|c|c|}
\hline \multicolumn{6}{|c|}{ TABLE 2} \\
Mean trace metal concentrations in \\
experimental soil samples in the vicinity of \\
Thohoyandou roads \\
\hline Road name & \multicolumn{5}{|c|}{ Mean concentrations (mg/kg) } \\
\cline { 2 - 6 } & $\mathbf{C u}$ & $\mathbf{Z n}$ & $\mathbf{C r}$ & $\mathbf{P b}$ & $\mathbf{C d}$ \\
\hline Sibasa & 0.42 & 0.84 & 0.43 & 21.04 & 0.18 \\
Univen & 0.28 & 0.85 & 0.55 & 13.31 & 0.23 \\
Punda Maria & 0.52 & 1.05 & 0.38 & 26.07 & 0.66 \\
Overall mean & 0.41 & 0.91 & 0.45 & 20.14 & 0.36 \\
\hline
\end{tabular}

\begin{tabular}{|l|l|l|l|l|l|l|}
\hline \multicolumn{7}{|c|}{ TABLE 3 } \\
Trace metal concentrations in 'control' plant \\
samples in the vicinity of Thohoyandou roads
\end{tabular}

\begin{tabular}{|c|c|c|c|c|c|}
\hline \multicolumn{6}{|c|}{$\begin{array}{c}\text { TABLE } 4 \\
\text { Mean trace metal concentrations in ex- } \\
\text { perimental plant samples in the vicinity } \\
\text { of Thohoyandou roads }\end{array}$} \\
\hline \multirow[t]{2}{*}{ Road name } & \multicolumn{5}{|c|}{ Concentrations (mg/kg) } \\
\hline & $\mathrm{Cu}$ & $\mathrm{Zn}$ & $\mathrm{Cr}$ & $\mathrm{Pb}$ & Cd \\
\hline Sibasa & 0.21 & 0.37 & 0.37 & 12.12 & 0.45 \\
\hline Univen & 0.17 & 0.17 & 0.24 & 10.55 & 0.23 \\
\hline Punda Maria & 0.13 & 1.13 & 0.13 & 20.73 & 0.23 \\
\hline Overall mean & 0.17 & 0.56 & 0.25 & 14.47 & 0.30 \\
\hline
\end{tabular}

\section{Metal levels in plants and soil}

The mean concentrations of $\mathrm{Cu}, \mathrm{Zn}, \mathrm{Cr}, \mathrm{Pb}$ and $\mathrm{Cd}$ in both the 'control' and the experimental samples are shown in Tables 1 to 4 . All five elements show higher mean concentrations in the experimental samples than in the 'controls' for most of the road studies except for $\mathrm{Cu}$ in samples obtained from Univen roadside soil ('control' $=0.72$ and exp. $=0.28$ ) and Punda Maria roadside vegetation ('control' $=0.22$ and exp. $=0.13$ ) and $\mathrm{Zn}$ in samples obtained from Univen roadside vegetation ('control' $=0.23$ and $\exp =0.17$ ). The overall mean 'controls' for $\mathrm{Cu}$ and $\mathrm{Zn}$ concentrations in these samples were slightly higher than the experimental samples. This suggests the possibility especially for $\mathrm{Cu}$ and $\mathrm{Zn}$ that in some cases, other sources are responsible. For the experimental soil samples, the overall mean concentrations of the five metals for the Thohoyandou roadsides were found to follow the following decreasing order: $\mathrm{Pb}>\mathrm{Zn}>\mathrm{Cr}>\mathrm{Cu}>\mathrm{Cd}$ (Table 2). For the vegetation experimental samples, however, the five metals were found to follow the following decreasing order: $\mathrm{Pb}>\mathrm{Zn}>\mathrm{Cd}>\mathrm{Cr}>$ $\mathrm{Cu}$ (Table 4). Other researchers have reported similar trends in related studies (Lagerwerff and Specht, 1970; Ward et al., 1977; Fatoki, 1996). Lagerwerff and Specht (1970) reported the following decreasing order; $\mathrm{Pb}>\mathrm{Zn}>\mathrm{Ni}>\mathrm{Cd}$ in a study on contamination of roadside soil and vegetation in the US while an order of $\mathrm{Pb}>\mathrm{Zn}>\mathrm{Ni}>\mathrm{Cu}>\mathrm{Cr}>\mathrm{Cd}$ was found by Ward et. al. (1977) in a study on heavy-metal pollution from automotive emissions and its effects on roadside soils and pasture species in New Zealand. In a study by Fatoki (1996) on the levels of $\mathrm{Zn}$ and $\mathrm{Cu}$ concentrations on roadside surface soils and vegetation in Alice, South Africa, Zn levels were found to be much higher than $\mathrm{Cu}$ in both sample types.

The concentration levels (Tables 2 and 4) found in this study are lower than those of other studies reported (Lagerwerff and Specht, 1970; Ward et al., 1977; Fatoki, 1996). As examples, Fatoki (1996) reported $\mathrm{Zn}$ and $\mathrm{Cu}$ concentrations of about 20 and $7 \mathrm{mg} / \mathrm{kg}$ for both soil sample and plant samples respectively; Lagerwerff and Specht (1970) reported concentrations ranging from 540 to $7.5 \mathrm{mg} / \mathrm{kg}$ for $\mathrm{Pb}, 162$ to $8.3 \mathrm{mg} / \mathrm{kg}$ for $\mathrm{Zn}, 1.82$ to $0.18 \mathrm{mg} / \mathrm{kg}$ for $\mathrm{Cd}$ for roadside soils depending on the traffic density and the distance from the roadside. Thohoyandou Town though is experiencing population and traffic increase it is still not as highly industrialised and urbanised. Major roads therefore do not have very high traffic densities compared to other industrialised towns within South Africa such as Johannesburg. Seasonal variation can also cause significant difference in the levels of metals found on roadside soil and vegetation as observed by Fatoki (1996). In the study conducted by Fatoki (1996), lower values were obtained for November samples than May. This was attributed to a washout process of metal deposition by rain during the summer months. This study was carried out in February 2002, the middle of summer in South Africa, when heavy fall was common. The mean $\mathrm{Pb}$ results in both plant and soil samples are lower than those reported by Okonkwo et al. (2003). Okonkwo et al. (2003) carried out a similar study in the same area but only for $\mathrm{Pb}$. Samples were collected in August 2000 which is the end of dry winter season and obtained concentrations above $200 \mathrm{mg} / \mathrm{kg}$ for $\mathrm{Pb}$ in both the soil and the plant samples. The marked difference with $\mathrm{Pb}$ results obtained in this study again can be attributed to wash-out process of deposited metals by rain.

\section{Metal levels and distance from the roadside}

The studied metal concentrations in soils generally decreased with distance from the road thus indicating their main source as motor traffic except for $\mathrm{Cd}$ in Punda Maria roadsides, $\mathrm{Cu}$ in Univen roadsides and $\mathrm{Cr}$ in Univen and Punda Maria roadsides (Fig. 3a-e). Univen roadside soil samples did not show consistent decrease in $\mathrm{Cu}$ concentration with distance like the other roadside soil samples (Fig. 3a). Univen and Punda Maria roadside soil samples also did not show consistent decrease in $\mathrm{Cr}$ concentrations with distance (Fig. 3c). Cd in Punda Maria roadside samples either remained the same or increased with roadside distance (Fig. 3e). The gradient of concentrations with distance from the roadside for soil samples generally decreased in the order $\mathrm{Pb}>\mathrm{Cu}>\mathrm{Cr}>\mathrm{Zn}>\mathrm{Cd}$. 
The metal concentrations in plant samples also generally decreased with distance from the road except for $\mathrm{Cu}, \mathrm{Zn}$ in Sibasa and Univen, $\mathrm{Cr}$ in Sibasa and Punda Maria, $\mathrm{Pb}$ in Sibasa, and $\mathrm{Cd}$ in Sibasa and Punda Maria (Fig. 4). In exceptional cases the concentrations of specific metals in plants either increased or remained the same between sampling points.

The concentrations of each metal in plants and soil were also observed to vary from one road to another. For example, in Tables 2 and 4 the highest concentrations of $\mathrm{Pb}$ in soils and plants was from Punda Maria roadside while the highest concentrations of $\mathrm{Cr}$ in soils and plants was from Univen and Sibasa, respectively. Specht (1970) and Fatoki (1996). The mean metal concentrations for both Punda Maria soil and plant samples were generally the highest. This is expected since Punda Maria road handles more traffic volume in the study area than the other two roads. Ward et al. (1977) studied in detail the relationship between traffic density and resulting roadside metal pollution. Roads that were found to have high traffic densities resulted in high levels of roadside pollution of $\mathrm{Cu}, \mathrm{Zn}, \mathrm{Pb}, \mathrm{Ni}, \mathrm{Cr}$ and $\mathrm{Cd}$ and vice versa.

\section{Soil metal and plant metal correlation}

An attempt was made to investigate any relationship between the metal in the soil to that found in the plant in the Sibasa roadside samples. This was chosen because the concentrations of a number of metals decreased with distance from the road. A metal. The correlation coefficients varied and were 0.991 for $\mathrm{Cu}$, 1.000 for $\mathrm{Zn}, 0.867$ for $\mathrm{Cr}, 0.995$ for $\mathrm{Pb}$ and 0.982 for $\mathrm{Cd}$. These values indicate the same metal source. This suggests motor traffic as the major source of these metals especially given that the concentrations decrease as one moves away from the roadside. Fatoki (1996), in a related study investigated the relationship between soil $\mathrm{Zn}$ and plant $\mathrm{Zn}$ and found values of correlation coefficients ranging from 0.961 to 0.995 . Since the $\mathrm{Cu}$ concentration of plant roadside samples from Punda Maria road did not decrease with distance, attempts were also made to correlate its soil metal to plant metal. A correlation coefficient of 0.397 was obtained. This suggests another source of $\mathrm{Cu}$ other than motor traffic in plant samples along this roadside. The correlation between trace metals in soil to that in the plant is very important from the human health aspect. In the study area, lots of vegetable crops are grown along the roadsides as a source of food. Further research is therefore needed to find out the levels of these metals in vegetable crops.

\section{Metal levels in water bodies}

Table 5 shows the levels of trace metals detected in water and sewage water samples. The metals levels were found to follow the following decreasing order; $\mathrm{Fe}>\mathrm{Zn}>\mathrm{Pt}>\mathrm{Cu}>\mathrm{Pd}$. $\mathrm{Pb}$ and $\mathrm{Cd}$ were not determined in the water samples while Fe, Pt and Pd were included. This is because in a study on the assessment of the biological wastewater treatment system in Thohoyandou (Manungufala, 2005) in which, $\mathrm{Pb}, \mathrm{Cu}, \mathrm{Fe}, \mathrm{Zn}$ and $\mathrm{Cd}$ were determined in the influent, effluent, upstream and downstream waters, $\mathrm{Pb}$ and $\mathrm{Cd}$ were found in very small quantities. The

Figure 3a-e (right)

Concentration of $\mathrm{Cu}, \mathrm{Zn}, \mathrm{Cr}, \mathrm{Pb}$ and $\mathrm{Cd}$ in soil samples along Sibasa, Univen and Punda Maria roads. Legend: •Sibasa road, \ Univen road, - Punda Maria road This has been observed in similar studies by Lagerwerff and strong relationship was found between its soil metal and plant
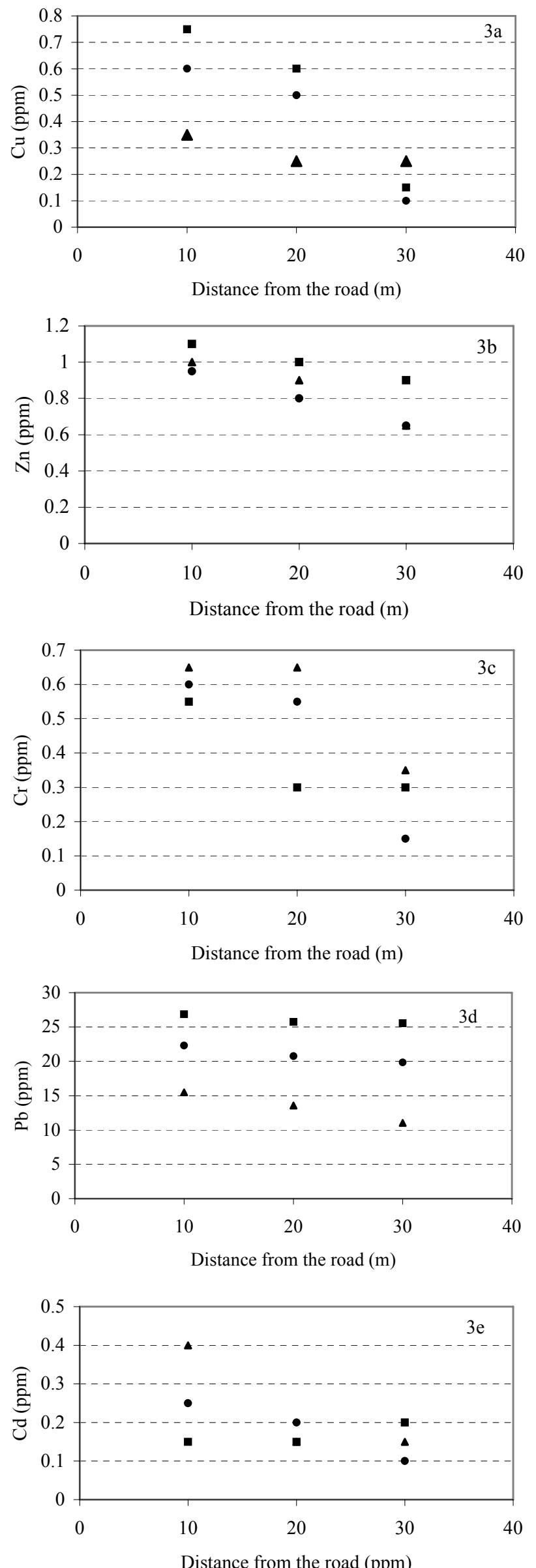
TABLE 5

Concentration of metal ions found in the river waters (RW), river waters mixed with sewage (RWMS) and sewage (S)

\begin{tabular}{|l|c|c|c|c|c|c|c|c|}
\hline Sample no & $\mathbf{p H}$ & $\begin{array}{c}\text { TSS } \\
(\mathbf{m g} / \mathbf{l})\end{array}$ & $\begin{array}{c}\text { Conduc- } \\
\text { tivity } \\
(\boldsymbol{\mu s / c m})\end{array}$ & $\begin{array}{c}\mathbf{Z n} \\
(\mathbf{m g} / \mathbf{l})\end{array}$ & $\begin{array}{c}\mathbf{C u} \\
(\mathbf{m g} / \mathbf{l})\end{array}$ & $\begin{array}{c}\mathbf{F e} \\
(\mathbf{m g} / \mathbf{l})\end{array}$ & $\begin{array}{c}\mathbf{P t} \\
(\mathbf{m g} / \mathbf{l})\end{array}$ & $\begin{array}{c}\mathbf{P d} \\
(\mathbf{m g} / \mathbf{l})\end{array}$ \\
\hline 1.Madanzhe-Sibasa RWMS & 7.00 & 96 & 194 & nd & nd & 0.0425 & 0.0074 & nd \\
2.Madanzhe-Nare RWMS & 6.83 & 52 & 282 & 0.0164 & nd & 0.1429 & 0.0075 & 0.0036 \\
3.Madanzhe RW & 7.79 & 152 & 62 & 0.0208 & nd & 0.1354 & nd & nd \\
4.Madanzhe-Ngovhela RW & 7.54 & 29 & 77 & 0.1543 & nd & 0.926 & nd & 0.0033 \\
5.Madanzhe- Univen RWMS & 7.21 & 30 & 169 & 0.110 & nd & 0.0718 & 0.0102 & nd \\
6. RWMS 15 M from Univen Pipe leaking & 6.65 & 108 & 210 & 0.0163 & nd & 0.1013 & 0.0069 & nd \\
7. RWMS 50 M from Univen Pipe leaking & 6.53 & 80 & 194 & 0.0112 & nd & 0.1001 & 0.0055 & nd \\
8.Univen RWMS & 7.70 & 260 & 444 & 0.2364 & nd & 1.303 & 0.0346 & 0.0059 \\
9.Univen S & 8.31 & 230 & 393 & 0.3774 & nd & 2.2645 & 0.0240 & 0.0261 \\
10.Mvudi RWMS & 7.67 & 80 & 154 & 0.0147 & nd & 0.0898 & 0.0090 & nd \\
11.Mvudi RWMS & 7.67 & 28 & 91 & 0.0489 & nd & 0.2691 & 0.0043 & nd \\
12.Mvudi park S & 8.54 & 66 & 367 & 0.3265 & 0.1594 & 2.1141 & 0.0285 & nd \\
13.Mvudi stadium RWMS & 6.94 & 100 & 90 & 0.0214 & nd & 0.1284 & 0.0093 & nd \\
14.Sewage treatment effluent & 7.65 & 194 & 285 & 0.0267 & 0.1077 & 0.1429 & 0.0804 & 0.0036 \\
15.15 M from sewage treatment outlet pipe & 7.31 & 180 & 112 & 0.0182 & nd & 0.0160 & 0.0075 & nd \\
16. Manini RW & 6.87 & 60 & 163 & 0.0105 & nd & 0.063 & 0.0044 & nd \\
17. Block G RW & 7.74 & 19 & 209 & 0.015 & 0.0034 & 0.0942 & 0.0104 & 0.0032 \\
18. Acacia Park RW & 6.78 & 40 & 276 & nd & nd & 0.0360 & 0.0053 & nd \\
19. Unit D RW & 6.98 & 30 & 290 & 0.0124 & nd & 0.0621 & 0.0053 & nd \\
20. Mvudi RW & 6.28 & 38 & 139 & 0.0167 & 0.1564 & 0.1035 & nd & nd \\
\hline
\end{tabular}

levels of trace metals in all the samples in the preceding study could be arranged in the following decreasing order: $\mathrm{Fe}>\mathrm{Zn}$ $>\mathrm{Cu}>\mathrm{Pb}>\mathrm{Cd}$. This is similar to the one determined above and suggests similar source. The decreasing order of the levels of trace metals in the water is different from that found in the roadside soil samples above of $\mathrm{Pb}>\mathrm{Zn}>\mathrm{Cr}>\mathrm{Cu}>\mathrm{Cd}$. This further suggests that very few metals from the roadside leach to the surrounding water bodies. The levels of trace metals in the water is below the South African Bureau of Standards (SABS) guidelines for fresh waters except for Fe which was higher than the standard value of $0.3 \mathrm{mg} / \ell$ in some samples. There is also a high chance that most trace metals deposit on the riverbeds as part of the sediment.

The $\mathrm{pH}$ of the water bodies (Table 5) generally tends towards alkaline. This is because of the leakage of the sewage in many parts directly into the rivers. High conductivity and total dissolved solids values support this. Since the $\mathrm{pH}$ is alkaline, it means most trace metals are highly adsorbed to dissolved solids. The $\mathrm{pH}$ of the water was within the SABS guidelines for drinking and domestic uses of water of between 6 and $9 \mathrm{pH}$ range that has also been validated by Okonkwo and Mothiba (2005). However, conductivity in most samples was higher than the SABS recommended value of $70 \mu \mathrm{s} / \mathrm{cm}$

\section{Sources of metals in the roadside soils and sewage system}

\section{Roadside soils}

The source of $\mathrm{Pb}$ is obviously leaded gasoline as has been established in the literature. This has also been recently reported by Okonkwo et al. (2003). According to South African national government, leaded gasoline is supposed to be phased out in the year 2006 because of pollution problems. Unleaded petrol, which was introduced into the South African market in 1996 (WHO, 2002), will therefore become the sole commercial gasoline. Currently, filling stations have options for either leaded or unleaded gasoline. Approximately $75 \%$ of motor traffic is still using leaded gasoline (WHO, 2002).

The study by Lagerwerff and Specht (1970) has suggested that motor traffic lubricating oils are the major sources of $\mathrm{Zn}$ and $\mathrm{Cd}$ as part of additives and impurities, respectively. $\mathrm{Zn}$ and $\mathrm{Cd}$ were also reported in the motor traffic car tyres by the same authors. $\mathrm{Cr}$ is used in chrome plating of many motor traffic parts while $\mathrm{Cu}$ is also a common constituent of many motorcar components such as engines and chassis (Ward et al., 1977). The fact that these metals were found along roadside soil and vegetation is probably due to mechanical wear and tear that deposits these metals in the fine dust of the roadway from the surrounding environment.

\section{Sewage system}

Sorme and Lagerkvist (2002) reported in detail the major sources of trace metals like $\mathrm{Cu}, \mathrm{Zn}, \mathrm{Ni}$ and $\mathrm{Cr}$ in sewage. In their study, the largest sources of $\mathrm{Cu}$ in sewage were found to be tap water and roofs. For $\mathrm{Zn}$, the largest sources were found to be galvanised household materials and car washes. The levels were found to follow the following decreasing order; $\mathrm{Zn}>\mathrm{Cu}>\mathrm{Ni}>$ $\mathrm{Cr}>\mathrm{Pb}>\mathrm{Cd}>\mathrm{Hg}$. Among the household items that were found to contain high amount of trace metals are food, pipes, taps and drinking water. These findings could in part explain why sewage water is the major source of trace metals in the rivers within Thohoyandou. The presence of Pt and Pd is, however, interesting since they have not been reported before in the sewage system to our knowledge. It could be due to the fact that these metals are now used as components of household items such as jewellery that later find their way into the sewage system. They may also 


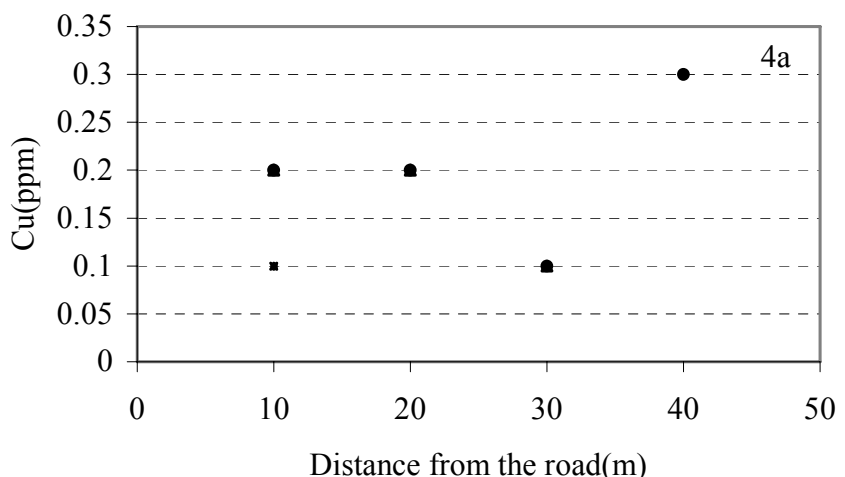

Distance from the $\operatorname{road}(\mathrm{m})$
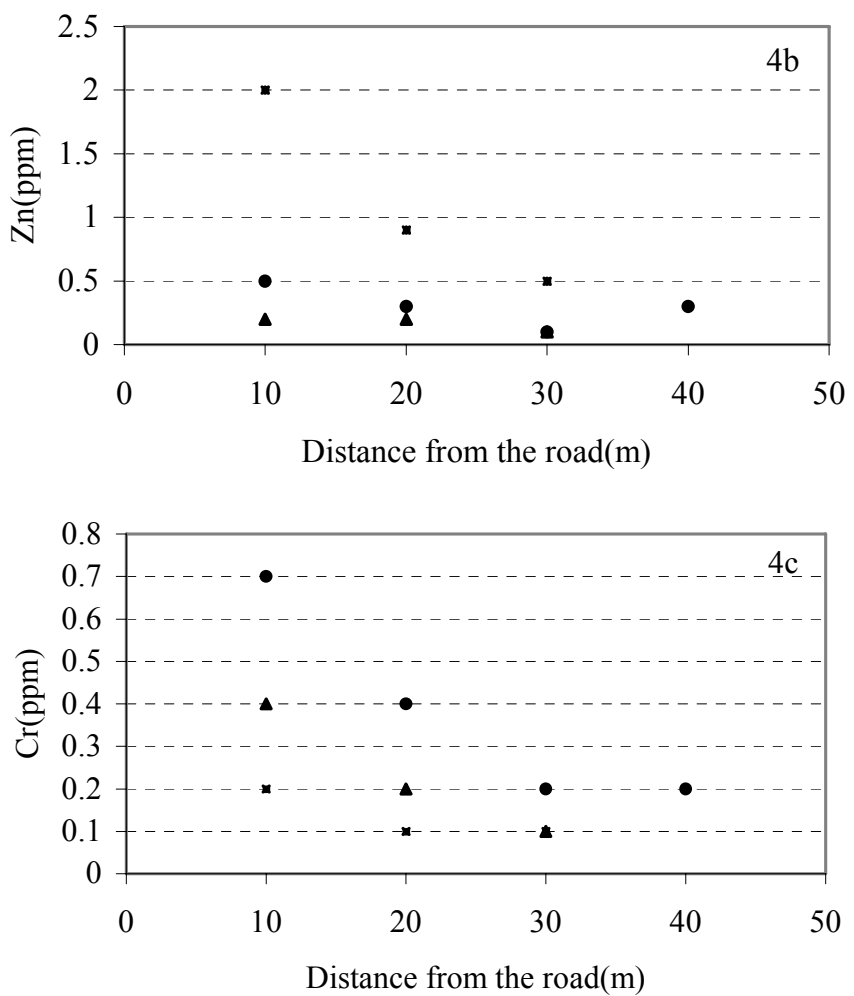

have been released by automobile catalytic converters and found their way into sources of water supply or open sewer drainage systems.

\section{Acknowledgements}

The authors would like to thank the following: National Research Foundation of South Africa for funding, Prof. Jonathan Okonkwo of Tshwane University of Technology (South Africa) for initial support and advice, and Dr Bobby Naidoo of the Limpopo University (South Africa) (formerly University of the North) for help in the analysis of soil and vegetation samples.

\section{References}

ALLOWAYS BJ (1995) Heavy Metals in Soils (2 $2^{\text {nd }}$ edn.) Chapman and Hall, London, U.K.

FATOKI OS (1996) Trace zinc and copper concentration in roadside surface soils and vegetation: A measurement of local atmospheric pollution in Alice, South Africa. Environ. Intern. 22 759-762.

FATOKI OS and AYODELE ET (1991) Zinc and copper in tree barks as indicators of environmental pollution. Environ. Intern. 17 455-460.
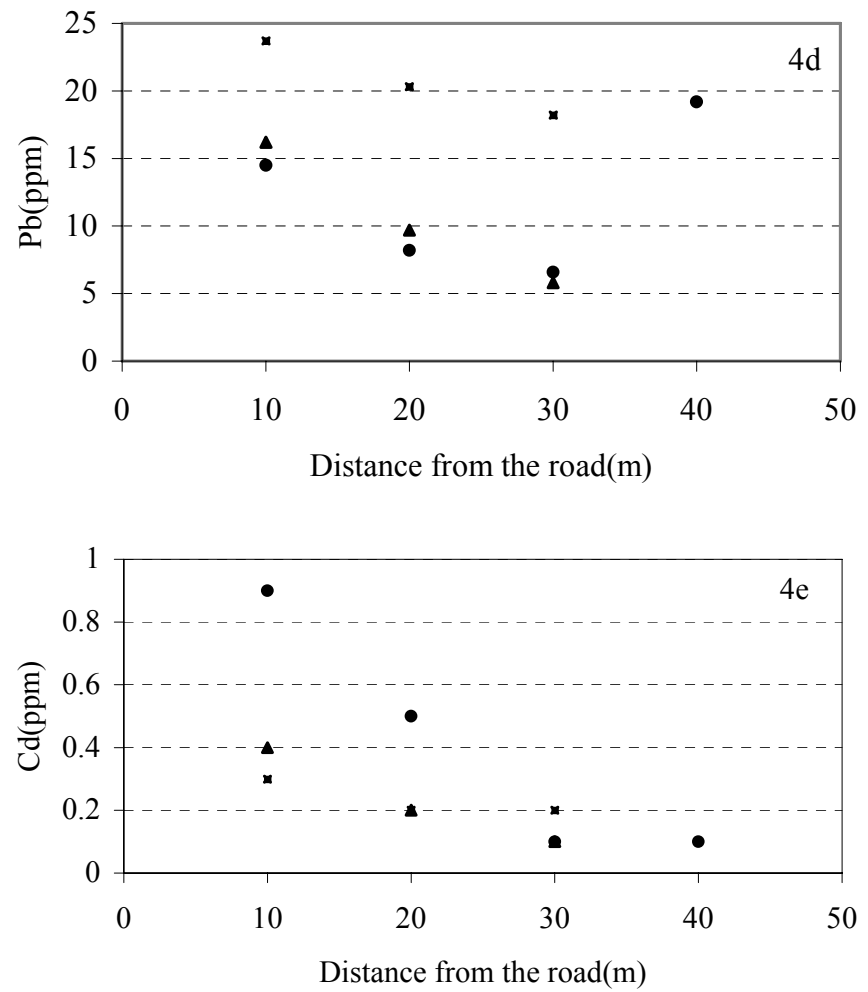
Concentrations of $\mathrm{Cu}, \mathrm{Zn}, \mathrm{Cr}, \mathrm{Pb}$ and $\mathrm{Cd}$ in plant samples
along Sibasa, Univen and Punda Maria roads. Legend: •Sibasa road, $\Delta$ Univen road, - Punda Maria road

GOYER RA (1996) Toxic effects of metal ions. In: Klassen C (ed.) Casarett and Doull's Toxicology. Vol 5. McGraw Hill, New York.

LAGERWERFF JV and SPECHT AW (1970) Contamination of roadside soil and vegetation with cadmium, nickel, lead and zinc. Environ. Sci. Technol. 4 583-586.

MANUNGUFALA T (2005) An Evaluation of the Performance of Thohoyandou Biological Wastewater Treatment System in Thulamela Municipality, Limpopo Province. Masters degree thesis submitted at University of Venda for Science and Technology, South Africa.

MATHEE A and SCHIRNDING Y (2002) Lead Exposure Amongst South African Children. Report compiled by South African Medical Research Council and World Health Organisation, submitted to World Summit on Sustainable Development, Johannesburg, South Africa.

MOLDOVAN M, RAUCH S, GOMEZ M, PALACIOS MA and MORRISON GM (2001) Bioaccumulation of palladium, platinum and rhodium from urban particulates and sediments by freshwater isopod Asellus aquaticus. Water Res. 35 4175-4183.

MORTON O, PUCHETT H, HERNANDEZ E and LOUNEJEVA E (2001) Traffic-related platinum group elements (PGE) in soils from Mexico City. J. Geochem. Explor. 72 323-227.

NDOU LW (2002) Lead Concentration in Roadside Soils and Vegetation: A Measure of Motor Vehicle Pollution in Thohoyandou Town, Limpopo Province, South Africa. Masters degree thesis submitted 
at University of Venda for Science and Technology-South Africa.

NYRIAGU OJ (1988) A silent epidemic of environmental metal poisoning? Environ. Pollut. 50 139-161.

OKONKWO JO and MOTHIBA M (2005) Physico-chemical characteristics and pollution levels of heavy metals in the rivers in Thohoyandou, South Africa. J. Hydrol. 308 122-127.

OKONKWO JO, NDOU LW and MARAIS PJJG (2003) Lead concentration in roadside soils and vegetation: a measure of motor vehicle pollution in Thohoyandou town, South Africa. Int. J. Environ. Studies 60 2-3.

ONYARI JM, ODOUR FDO, ORATA F, WANDIGA SO, NJENGA GK and NYATEBE JO (2002) A survey of heavy metal pollution from automotive emissions in Kenya's urban environment. Department of Chemistry, University of Nairobi, Kenya. Paper presented at First Regional Conference on Trace Elements Research in Africa. Nairobi Kenya.
RAVINDRA K, BENCS L and GRIEKEN RV (2004) Platinum group elements in the environments and their health risk. Sci. Total Environ. 318 1-43.

SITHOLE SD, MOYO N and MACHEKA M (1993) An assessment of lead pollution from vehicle emissions along selected roadways in Harare, Zimbabwe. Intern. J. Environ. Anal. Chem. 53 1-12.

SÖRME L and LAGERKVIST R (2002) Sources of heavy metals in urban wastewater in Stockholm. Sci. Total Environ. 298 131-145.

WARD NI, BROOKS RR, ROBERTS E and BOSWELL CR (1977) Heavy metal pollution from automotive emissions and its effects on roadside soil and pasture species in New Zealand. Environ. Sci. Technol. 11 917-920.

WHO SOUTH AFRICA (2002) Protection of the human environment. Newsletter 3 (4). 